\title{
Isolation of phylogenetically diverse nonylphenol ethoxylate-degrading bacteria and characterization of their corresponding biotransformation pathways
}

\author{
Xin $\mathrm{Gu}^{\mathrm{a}}$, Yu Zhang ${ }^{\mathrm{a}, *}$, Jing Zhang ${ }^{\mathrm{a}}$, Min Yang ${ }^{\mathrm{a}, * *}$, Hideyuki Tamaki ${ }^{\mathrm{b}}$, Yoichi Kamagata ${ }^{\mathrm{b}, \mathrm{c}}$, Dong Li $^{\mathrm{a}}$ \\ a State Key Laboratory of Environmental Aquatic Chemistry, Research Center for Eco-Environmental Sciences, Chinese Academy of Sciences, P.O. Box 2871, Beijing 100085, China \\ ${ }^{\mathrm{b}}$ Institute for Biological Resources and Functions, National Institute of Advanced Industrial Science and Technology, Tsukuba, Ibaraki 305-8566, Japan \\ ${ }^{\mathrm{c}}$ Research Institute of Genome-Based Biofactory, National Institute of Advanced Industrial Science and Technology, Sapporo 062-8517, Japan
}

\section{A R T I C L E I N F O}

\section{Article history:}

Received 8 December 2009

Received in revised form 16 April 2010

Accepted 16 April 2010

Available online 10 May 2010

\section{Keywords:}

Nonylphenonl polyethoxylates

Degrading-bacteria

Biodegradation pathway

Aquatic environment

\begin{abstract}
A B S T R A C T
Most nonylphenol ethoxylate (NPEO)-degrading isolates have been assigned to $\gamma$-Proteobacteria, which is different from the results acquired by using molecular ecological techniques. To better understand the environmental fate of NPEOs, bacterial isolation strategy characterized by the use of gellan gum as a gelling reagent and a low concentration of target carbon source were used to isolate phylogenetically diverse NPEO-degrading bacteria from activated sludge, and the biotransformation pathways of the isolates were investigated. Eight NPEO-degrading isolates with high diversity were acquired, which were distributed among seven different genera: Pseudomonas, Sphingomonas, Sphingobium, Cupriavidus, Ralstonia, Achromobacter and Staphylococcus. The latter five genera have never been reported to be able to degrade NPEOs. Three biotransformation pathways of NPEOs were observed in the eight stains. Six strains belonging to $\alpha, \beta$ and $\gamma$ classes of Proteobacteria and Firmicutes phylum degraded NPEOs by initially shortening the EO chain and then oxidizing the terminal alcohol of the shortened NPEOs to the corresponding nonylphenoxy carboxylates (NPECs), which could explain most of the reported observations for the degradation of NPEOs in environment. An isolate (NP42a) belonging to the genus Sphingomonas degraded NPEOs through a non-oxidative pathway, with nonylphenol monoethoxylate $\left(\mathrm{NP}_{1} \mathrm{EO}\right)$ as the dominant product. Another isolate (NP47a) belonging to the genus Ralstonia degraded NPEOs by oxidizing the EO chain directly without the formation of short chain products.
\end{abstract}

(c) 2010 Elsevier Ltd. All rights reserved.

\section{Introduction}

Nonylphenol ethoxylates (NPEOs) are highly cost effective surfactants that are widely used in industrial, agricultural, commercial and household applications (Thiele et al., 1997). They reach wastewater treatment plants (WWTPs), in which they are incompletely degraded to short-chain NPEOs, nonylphenoxy carboxylates (NPECs), carboxyalkylphenol polyethoxycarboxylates (CAPECs), and nonylphenol (NP) (Ahel et al., 1994; Di Corcia et al., 1998a; Maguire, 1999; Ying et al., 2002; Montgomery-Brown and Reinhard, 2003; Gonzalez et al., 2007; Koh et al., 2008; Nagarnaik et al., 2010). Some metabolites such as NP and nonylphenol monoand diethoxylate $\left(\mathrm{NP}_{1} \mathrm{EO}\right.$ and $\left.\mathrm{NP}_{2} \mathrm{EO}\right)$ have long been focused because they act as estrogenic hormones in wildlife at low concentrations (Jobling et al., 1996; Routledge and Sumpter, 1996). Therefore, it is important to understand the fates of NPEOs from the viewpoint of environmental risk management.

\footnotetext{
* Corresponding author. Tel.: +86 106292 3475; fax: +86 1062923541

** Corresponding author. Tel.: +86 106292 3475; fax: +86 1062923541 .

E-mail addresses: zhangyu@rcees.ac.cn (Y. Zhang), yangmin@rcees.ac.cn (M. Yang).
}

The biodegradation of NPEOs is generally believed to start with the stepwise shortening of the ethoxy (EO) chain (Thiele et al., 1997; Montgomery-Brown and Reinhard, 2003). To date, two EO chain-shortening pathways have been elucidated using pure cultures: (i) non-oxidative EO chain (hydroxyl shifts) exo-cleavage with short-chain NPEOs as the main metabolites ( $n=2$ or 3$)$, which occurs through the release of one molecule of acetaldehyde at each step (Fig. 1A) (John and White, 1998; Lu et al., 2008) and (ii) EO chain oxidation and exo-cleavage with short chains of NPEOs and NPECs as the main metabolites ( $n=2$ or 3 ), which occurs through release of one molecule of glyoxylic acid at each step (Fig. 1B) (Sato et al., 2001, 2003; Liu et al., 2006). However, many laboratory and field studies have shown that $\mathrm{NP}_{1} \mathrm{EO}$ or CAPECs are the main metabolites (Ahel et al., 1994; Di Corcia et al., 1998a; Jonkers et al., 2001), which cannot be explained well by the above pathways. On the other hand, based on an evaluation of NPEO metabolites in WWTPs, it was suggested that NPEOs were gradually shortened, after which the short-chain NPEOs were directly oxidized to their corresponding NPECs without exo-cleavage (Ahel et al., 1994; Di Corcia et al., 1998a; Montgomery-Brown and Reinhard, 2003). So it is possible that some other pathways might exist, which requires further studies using pure cultures. 
(A)

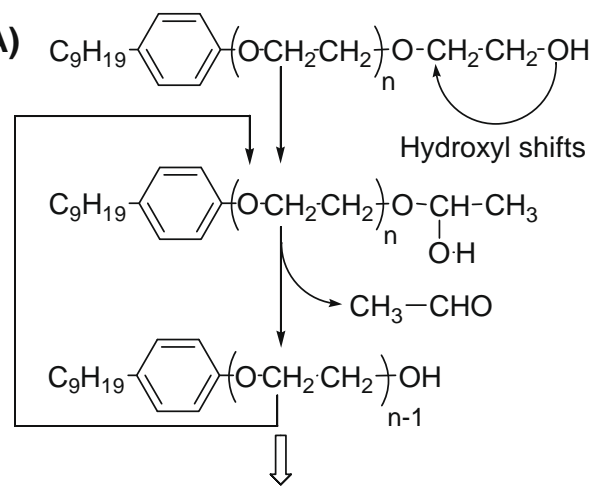

Accumulating NPEOs with $n=2$ or 3

(B)

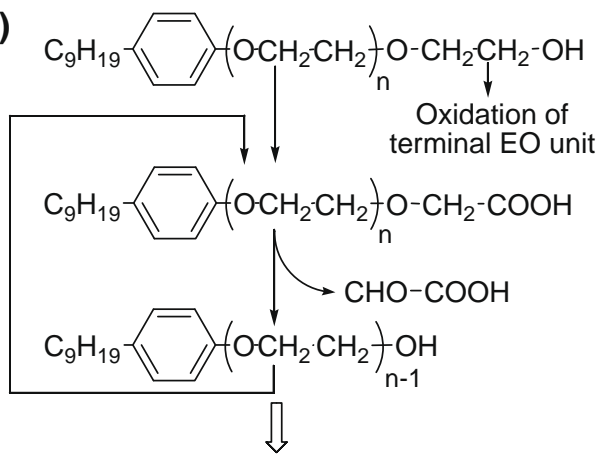

Accumulating NPEOs and NPECs with $n=2$ or 3

Fig. 1. Generally proposed aerobic biodegradation pathway of NPEOs (John and White, 1998; Sato et al., 2001). (A) Hydroxyl shift cleavage model, and (B) terminal oxidation cleavage model. The exact structure of the alkyl chain is not specified.

At the same time, bacteria capable of degrading NPEOs or octylphenol ethoxylates (OPEOs) have been isolated from a wide variety of environments, including activated sludge (Maki et al., 1994; John and White, 1998; Barberio et al., 2001; Liu et al., 2006), sea water (Nguyen and Sigoillot, 1997), contaminated soil (Sato et al., 2001) and sediment (Chen et al., 2005). Except for several OPEOdegrading bacteria belonging to $\beta$ - and $\alpha$-Proteobacteria, such as Burkholderia cepacia and Sphingomonas sp., most NPEO- or OPEOdegrading isolates have been assigned to $\gamma$-Proteobacteria (mainly Pseudomonas spp.) (Maki et al., 1994; Nguyen and Sigoillot, 1997; John and White, 1998; Chen et al., 2005). However, community structure analysis of NPEO-enriched activated sludge using multiple molecular ecological techniques has demonstrated that bacteria affiliated with $\alpha$ - and $\beta$-Proteobacteria are dominant in NPEOamended reactors, suggesting that these bacteria might be involved in the degradation of NPEOs (Lozada et al., 2004, 2006). So it is possible that pure cultures acquired through conventional isolation methods may not represent the actual distribution of NPEO-degrading bacteria in the environment, which might have affected the results of pathway researches.

Recently, strategies such as adjusting the gelling agent used in the solid medium and avoiding the use of nutrient-rich growth media have successfully narrowed the gaps in the results between molecular and cultivation-based analyses (Janssen et al., 2002; Tamaki et al., 2005). Gellan gum can effectively increase the cultivability of organisms and overcome some of the toxic effects that agar has on various groups of microorganisms. In addition, the clarity of the gum gels makes it possible to detect micro-colonies in plates that could not be seen on agar. For example, the percentage of $\beta$-Proteobacteria isolates recovered from lake sediment by gellan gumbased cultivation (40\%) was much higher than that recovered by agar-based cultivation (3.3\%) (Tamaki et al., 2005). At the same time, high concentrations of target organic compounds normally used for enrichment tend to favor fast-growing species (Ferrari et al., 2005).

The purpose of this study was to isolate phylogenetically diverse NPEO-degrading bacteria using the above cultivation strategy characterized by the use of gellan gum as a gelling reagent and a low concentration of target carbon source. The degradation pathways of NPEOs for the acquired isolates were then characterized. This study will improve the understanding of the fates of NPEOs in the environment.

\section{Materials and methods}

\subsection{Reagents and chemicals}

Technical grade NPEO surfactant mixtures with an ethoxylate range of 4-19 and an average EO chain length of $9\left(\mathrm{NP}_{\mathrm{avg}} \mathrm{EO}\right)$ and 4-n-NP (used as an internal standard for GC-MS analysis) were obtained from Tokyo Chemical Industry Co., Ltd. (Tokyo, Japan). NH2 column $(250 \times 4.6 \mathrm{~mm}, 5 \mu \mathrm{L}$, Agilent-Zorbax, USA $)$ with gradient elution coupled to UV detection $(277 \mathrm{~nm})$ to detect the distribution of EO chain (Ahel and Giger, 1985). Since the molar percentage of short chain NPEO oligomers (NP1-3EO) was less than $2 \%$ of the total mixtures as shown in Fig. S1 (Supplementary Material), its contribution to technical surfactant mixtures was omitted in this study. Mixed NPEO standards, NPECs standards with EO chain lengths ranging from 0 to 9 corresponding to $\mathrm{NP}_{1} \mathrm{EC}$ to $\mathrm{NP}_{10} \mathrm{EC}$, and NP were obtained from Hayashi Pure Chemicals (Osaka, Japan). N,O-bis(trimethylsilyl)trifluoroacetamide (BSTFA) containing $1 \%$ trimethyl-chlorosilane (TMCS), which was used for trimethylsilylation, as well as gellan gum and agar used as gelling agents, were obtained from Supelco (Bellefonte, PA, USA). Pure linear alcohol ethoxylates $\left(\mathrm{AEO}_{8}\right)$ and 2,4-dinitrophenylhydrazine (DNPH) were obtained from Fluka AG (Buchs, Switzerland). All organic solvents (HPLC grade) were obtained from Fisher Company (Muskegon, MI, USA). All water (18.2 M $\Omega$ ) used in this study was purified using a PURIC-MXII apparatus (Organo, Japan).

\subsection{Screening and identification of NPEO-degrading bacteria}

A sludge sample was collected from an activated sludge reactor used to treat NPEO-containing wastewater (Zhang et al., 2008a) and inoculated into modified PE03 medium containing $\mathrm{NP}_{\mathrm{av} 9} \mathrm{EO}$ ( 50 or $500 \mathrm{mg} \mathrm{L}^{-1}$ ) as the only carbon source. One liter of the modified PE03 medium contained: $0.38 \mathrm{~g}$ of $\mathrm{KH}_{2} \mathrm{PO}_{4}, 0.39 \mathrm{~g}$ of $\mathrm{K}_{2} \mathrm{HPO}_{4}$, $0.5 \mathrm{~g}$ of $\left(\mathrm{NH}_{4}\right)_{2} \mathrm{SO}_{4}, 5 \mathrm{~mL}$ of basal salts solution and $1 \mathrm{~mL}$ of vitamin solution (Hanada et al., 1995). The cultures were then incubated aerobically at $30{ }^{\circ} \mathrm{C}$ with shaking at $140 \mathrm{rpm}$. The enrichment cycles were repeated at 10-day intervals for 6 months. Finally, $100 \mu \mathrm{L}$ of culture broth diluted appropriately was spread on PE03-NP ${ }_{\mathrm{av} 9} \mathrm{EO}$ ( 50 or $500 \mathrm{mg} \mathrm{L}^{-1}$ ) gellan gum or agar plates and then incubated at $30^{\circ} \mathrm{C}$ in the dark for 3 days. Next, 16 morphologically distinct colonies were selected, purified and tested for their ability to degrade $\mathrm{NP}_{\mathrm{av} 9} \mathrm{EO}$. NPEO-degrading strains were further identified by amplification of their 16S rRNA genes using universal bacterial primers $27 \mathrm{~F}$ and 1492R (Lane, 1991). The nucleotide sequences of the $16 \mathrm{~S}$ rRNA genes obtained were then submitted to GenBank and assigned the following accession numbers: NP31a (EU580701), NP213b (EU580710), NP47a (EU580702), NP15b (EU580707), NP22b (EU580697), NP41b (EU580708), NP42a (EU580703), and NP426a (EU580698).

\subsection{Biodegradation of NPav9EO using pure cultures}

All isolates were previously grown to the log phase in LuriaBertani liquid medium supplemented with $\mathrm{NP}_{\mathrm{avg}} \mathrm{EO}\left(500 \mathrm{mg} \mathrm{L}^{-1}\right)$. 
A $100-\mu \mathrm{L}$ aliquot of the culture medium, which had an optical density at $600 \mathrm{~nm}$ that was adjusted to 0.5 , was then used to inoculate $250-\mathrm{mL}$ Erlenmeyer flasks containing $100 \mathrm{~mL}$ of PE03-NP ${ }_{\mathrm{av} 9} \mathrm{EO}$ (500 $\mathrm{mg} \mathrm{L}^{-1}$ ) medium. The samples were then subjected to constant shaking at $140 \mathrm{rpm}$ and $30^{\circ} \mathrm{C}$ for 20 days and the growth was evaluated by measuring the optical density at $600 \mathrm{~nm}$ using a spectrophotometer (Hitachi, UV3010). All assays were conducted in duplicate and test blanks were added to measure the abiotic losses.

After a designated time, the culture medium $(2 \mathrm{~mL})$ was collected from the test tubes, stabilized with $20 \mu \mathrm{L}$ of formaldehyde and acidified to $\mathrm{pH} 2$ with $\mathrm{HCl}$. The medium was then extracted using an equal volume of ethyl acetate/methanol (7:3, v/v) twice by shaking the mixture vigorously. The collected organic phases were then blown dry under a gentle flow of nitrogen. For LC-MS analysis, dried samples were redissolved in $1 \mathrm{~mL}$ of methanol/ Nanopure water $1: 1(\mathrm{v} / \mathrm{v})$. The recoveries of the NP, NPEOs, and NPECs ranged from $72.5 \%$ to $96.4 \%$.

\subsection{Biodegradation of $N P_{11} E O$ using resting cells}

Cells grown in PE03-NP ${ }_{\mathrm{av} 9} \mathrm{EO}\left(500 \mathrm{mg} \mathrm{L}^{-1}\right.$ ) medium up to the late log phase were harvested by centrifugation ( $8500 \mathrm{~g}, 10 \mathrm{~min}$ ), washed twice with sterile distilled water and then used as resting cells. The biodegradation tests using resting cells were similar to the $\mathrm{NP}_{\mathrm{av} 9} \mathrm{EO}$ degradation tests, except that $\mathrm{NP}_{11} \mathrm{EO}\left(35 \mathrm{mg} \mathrm{L}^{-1}\right)$ was used instead of $\mathrm{NP}_{\mathrm{av} 9} \mathrm{EO}$, and $50-\mathrm{mL}$ Erlenmeyer flasks that each contained $20 \mathrm{~mL}$ of PE03 medium were used for the reactions.

Individual NPEO oligomer $\left(\mathrm{NP}_{11} \mathrm{EO}\right)$ was prepared from the $\mathrm{NP}_{\mathrm{a}}$ ${ }_{\mathrm{v} 9} \mathrm{EO}$ mixture by normal-phase HPLC using a previously described method (Hayashi et al., 2005). Gradient separation was performed on a Agilent-Zorbax $\mathrm{NH}_{2}$ column $(4.6 \mathrm{~mm} \times 250 \mathrm{~mm}, 5 \mu \mathrm{m})$ using $n$-hexane/2-propanol $(93: 7, \mathrm{v} / \mathrm{v})$ and 2-propanol/water as the mobile phases $(95: 5, \mathrm{v} / \mathrm{v})(27)$. The $\mathrm{NP}_{11} \mathrm{EO}$ fraction was obtained by collecting the eluate over the corresponding period and then evaporating the sample to dryness under a gentle nitrogen stream.

\subsection{Preparation and use of cell extracts to detect the intermediates}

Strains were incubated in 500-mL Erlenmeyer flasks containing $200 \mathrm{~mL}$ of PE03-NP ${ }_{\mathrm{av} 9} \mathrm{EO}\left(500 \mathrm{mg} \mathrm{L}^{-1}\right)$ medium. Cells were grown to the late log phase and then pelleted by centrifugation $(8000 \mathrm{~g}$, $20 \mathrm{~min}$ ), washed once with $10 \mathrm{mM}$ potassium phosphate buffer ( $\mathrm{pH} 7.0$ ), washed twice with $20 \mathrm{mM}$ Tris-HCl buffer ( $\mathrm{pH} 8.0$ ), suspended in the same buffer, disrupted by sonication at $4{ }^{\circ} \mathrm{C}$ (eight times for $15 \mathrm{~s}$ each with a $10 \mathrm{~s}$ interval) and centrifuged $(10,000 \mathrm{~g}, 15 \mathrm{~min})$. The resultant supernatants were then used as cell extracts after filtration through $0.2 \mu \mathrm{m}$ pore filters. Aliquots $(1 \mathrm{~mL})$ of the cell extracts were mixed with $1 \mathrm{~mL}$ of PE03 medium supplemented with $\mathrm{NP}_{\mathrm{av} 9} \mathrm{EO}$ or $\mathrm{AEO}_{8}\left(2000 \mathrm{mg} \mathrm{L}^{-1}\right)$ and then incubated at $28{ }^{\circ} \mathrm{C}$ for $4 \mathrm{~h}$.

Formation of aldehydic compounds from NPEOs in the cell extracts was detected by derivatization with DNPH combined with LC/MS (Richardson et al., 2000). The reagent solution was prepared by dissolving $20 \mathrm{mg}$ of DNPH in $15 \mathrm{~mL}$ of a solution that contained $\mathrm{HCl}\left(\sim 12 \mathrm{~mol} \mathrm{~L}^{-1}\right)$, water, and acetonitrile at a ratio of 2:5:1 $(\mathrm{v} / \mathrm{v})$. Derivatization was conducted by adding $500 \mu \mathrm{L}$ of the reagent solution to the sample. After $12 \mathrm{~h}$ of reaction $\left(40{ }^{\circ} \mathrm{C}\right)$, the solution was injected directly into the LC/MS system using a mobile phase consisting of acetonitrile and $5 \mathrm{mmol} \mathrm{L}^{-1}$ ammonium acetate solution. Changes in the percentage of acetonitrile were as follows: $30 \%$ at time zero, $95 \%$ at $25 \mathrm{~min}$, and $100 \%$ at $30 \mathrm{~min}$. The flow rate of the mobile phase was $0.2 \mathrm{~mL} \mathrm{~min}^{-1}$. Aldehydic compounds were detected by selected ion recording (SIR) of the corresponding (M$\mathrm{H})^{-}$ions in negative ion mode.

\subsection{Analysis of NPEOs and related compounds}

Simultaneous analysis of the NPEOs with long chains and NPECs was conducted using a Waters LC/MS system (Alliance 2690 HPLC system linked to a Micromass ZQ 4000) equipped with a Waters Symmetry Shield ${ }^{\mathrm{TM}} \mathrm{RP} 18$ column $(150 \times 2.1 \mathrm{~mm}, 3.5 \mu \mathrm{m})$ as previously (Zhang et al., 2007). The mobile phase was a mixture of $5 \mathrm{mmol} \mathrm{L}^{-1}$ ammonium acetate solution (A) and pure methanol (B). All analyses were performed in SIR mode using the deprotonated molecular ions of NPECs during negative ionization and the ammonium adducts of NPEOs in positive mode. The method recoveries ranged from $75 \%$ to $98 \%$ and the relative standard deviation (RSD) was below $12 \%$. Instrumental limits of detection and linear range were $25 \mathrm{pg}$ and $2.5-500 \mu \mathrm{g} \mathrm{L}^{-1}$ for $\mathrm{NP}_{1-10} \mathrm{EC}$, respectively. The concentration (0.5-39.3 $\left.\mathrm{g} \mathrm{L}^{-1}\right)$, SIR peak S/N (38-486), detection limit $(0.4-4.6 \mathrm{pg})$ of individual NPEO $(n>3)$ oligomer in $300 \mu \mathrm{g} \mathrm{L}^{-1}$ of $\mathrm{NP}_{\mathrm{av} 9} \mathrm{EO}$ were calculated based on the assumption of the same molar absorption coefficient (Table S1, Supplementary Material).

Short-chain NPEOs $\left(\mathrm{NP}_{2} \mathrm{EO}\right.$ and $\left.\mathrm{NP}_{1} \mathrm{EO}\right)$ and $\mathrm{NP}$ were analyzed using a gas chromatograph (Agilent Technologies, $6890 \mathrm{GC}$ ) interfaced with a DB-5MS capillary column $(30 \mathrm{~m} \times 0.25 \mathrm{~mm} \times$ $0.25 \mu \mathrm{m}$ ) and a mass spectrometer (Agilent Technologies, 5975i MSD) (Isobe et al., 2001). Due to the coelution problems (Crescenzi et al., 1995), the signal intensity of short-chain NPEOs $(n=1-3)$ was much lower than that of long chain NPEOs oligomers. So, GC-MS, which could provide reliable identification and high sensitivity, was used for analyzing short-chain NPEOs (Thiele et al., 1997). Briefly, the dried samples were redissolved in $n$-hexane, derivatized with BSTFA, and then subjected to GC-MS analysis. The GC column temperature was programmed to increase from $50{ }^{\circ} \mathrm{C}$ (initial equilibrium time $2 \mathrm{~min}$ ) to $200^{\circ} \mathrm{C}$ via a ramp of $20^{\circ} \mathrm{C} \mathrm{min}^{-1}$, from 200 to $260{ }^{\circ} \mathrm{C}$ via a ramp of $5^{\circ} \mathrm{C} \mathrm{min}^{-1}$, and from 260 to $280^{\circ} \mathrm{C}$ via a ramp of $20^{\circ} \mathrm{C} \mathrm{min}^{-1}$, after which it was maintained at $280^{\circ} \mathrm{C}$ for $2 \mathrm{~min}$. Helium carrier gas was maintained at a constant flow rate of $1 \mathrm{~mL} \mathrm{~min}{ }^{-1}$. Compounds were identified by comparison with previously published results (Isobe et al., 2001) and quantified in selective ion monitoring mode (SIM).

\section{Results and discussion}

\subsection{Taxonomic characteristics of NPEO-degrading isolates}

Eight NPEO-degrading bacterial strains were successfully isolated from activated sludge acclimated with $\mathrm{NP}_{\mathrm{av} 9} \mathrm{EO}$. The $16 \mathrm{~S}$ rRNA sequences of strains NP42a, NP31a, NP213b, NP15b and NP426a were >99\% homologous with Sphingomonas sp. LB126, Alcaligenes sp. NyZ215, Cupriavidus sp. KU-26, Pseudomonas putida KT2440, and Staphylococcus haemolyticus, respectively. The sequences of NP41b, NP22b, and NP47a were 96-98\% homologous with Sphingomonas sp. JS5, Sphingobium sp. TP340-2, and Ralatonia sp. BPC3, respectively.

These isolates, which were distributed widely in the $\alpha, \beta$ and $\gamma$ classes of Proteobacteria and the Firmicutes phylum, could be assigned to seven different genera: Pseudomonas (NP15b), Sphingomonas (NP41b, NP42a), Sphingobium (NP22b), Cupriavidus (NP213b), Ralstonia (NP47a), Achromobacter (NP31a) and Staphylococcus (NP426a) (Fig. 2). Among the eight isolates, only NP15b (Pseudomonas) was found to be closely related to previously reported NPEO-degrading bacteria (Maki et al., 1994; Nguyen and Sigoillot, 1997; John and White, 1998; Barberio et al., 2001; Liu et al., 2006). No members of the latter five genera have previously been identified as NPEO degraders. Among the eight NPEO-degrading isolates, three isolates belonged to $\beta$-Proteobacteria (the order Burkholderiales) and three to $\alpha$-Proteobacteria (Sphingomonas and 


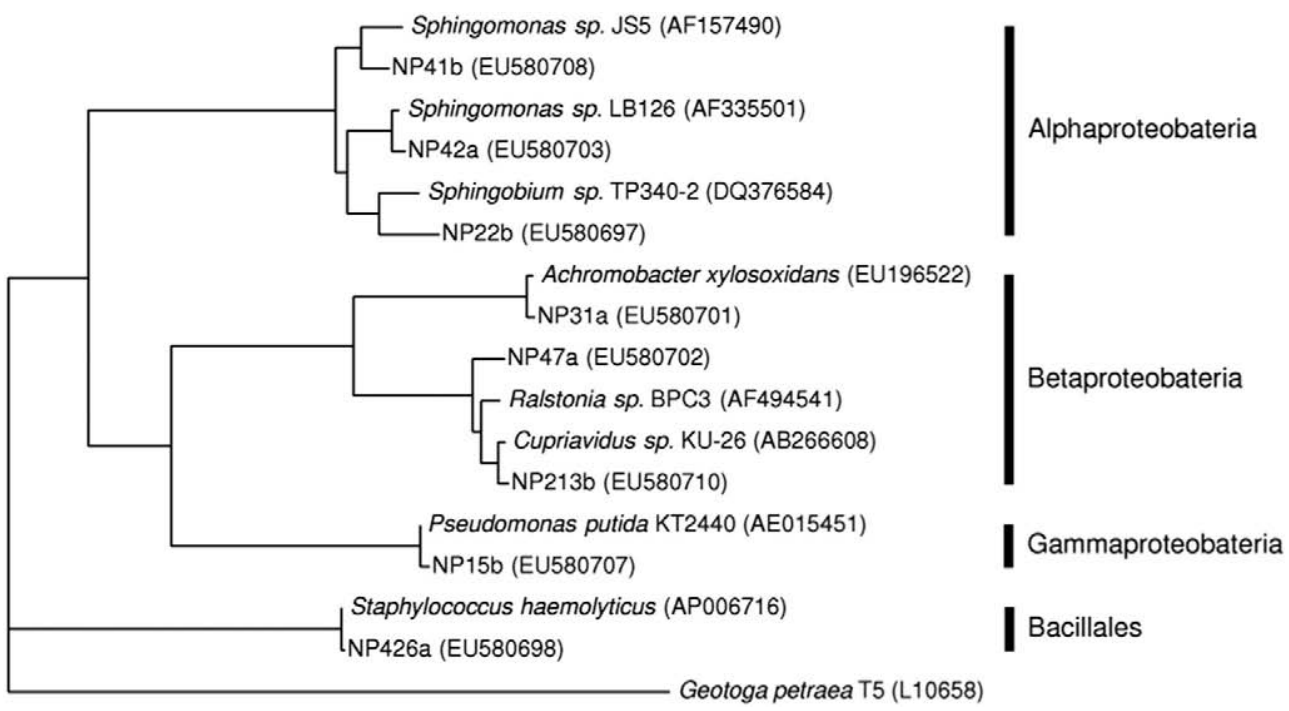

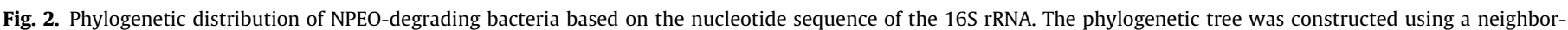

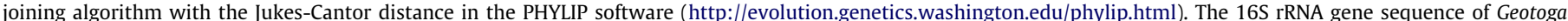

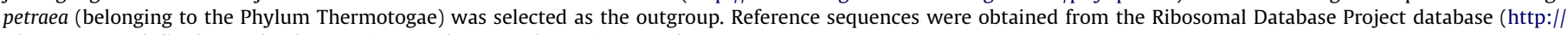
rdp.cme.msu.edu/). The Genbank accession numbers are shown in parentheses.

Sphingobium). This was in accordance with the culture independent (molecular) studies showing that $\alpha$ - and $\beta$-Proteobacteria are dominant in NPEO-amended reactors (especially the order Burkholderiales and the genus Sphingomonas) (Lozada et al., 2004, 2006; Zhang et al., 2008b).

It is clear that the strategy used to isolate NPEO-degrading bacteria was successful in the present study. While eight strains were identified using the gellan gum based media, only three (NP22b, NP213b, NP15b) were obtained on the agar based media (data not shown), showing that the use of gellan gum might have resulted in the isolation of phylogenetically diverse NPEO-degrading species. On the other hand, only NP15b (isolated by both agar and gellan gum) and NP31a (isolated by gellan gum) were acquired when using $500 \mathrm{mg} \mathrm{L}^{-1}$ of NPEOs, suggesting that keeping a relatively low concentration of NPEOs might also be important for acquiring phylogenetically diverse isolates.

\subsection{NPEO biotransformation pathway studies}

3.2.1. Pathway 1: hydroxyl shift cleavage of NPEOs with $N P_{1} E O$ as the major degradation product

Strain NP42a, which belongs to the Sphingomonas genus ( $\alpha$-Proteobacteria), was capable of degrading $>95 \%$ (molar percentage) of the $\mathrm{NP}_{\mathrm{av}} \mathrm{EO}$ within 2 days, and its growth was correlated with the disappearance of $\mathrm{NP}_{\mathrm{av} 9} \mathrm{EO}$ (Fig. $3 \mathrm{~A}$ ). $\mathrm{NP}_{1} \mathrm{EO}$ and $\mathrm{NP}_{2} \mathrm{EO}$ were the primary degradation products at the beginning, but $\mathrm{NP}_{1} \mathrm{EO}$ soon became the dominant products (Fig. 3B). NPECs were not formed throughout the whole period, which suggests that NPEOs should be biodegraded through a non-oxidative pathway. A mass balance at different sampling times for strain NP42a was summarized in Table S2 (Supplementary Material). The main metabolites detected $\left(\mathrm{NP}_{1-3} \mathrm{EO}\right)$ accounted for about $4.3-84 \%$ molar percentage of $\mathrm{NP}_{\mathrm{a}-}$ ${ }_{\mathrm{v} 9} \mathrm{EO}$ transformed during 15 days, which is in accordance with other studies (Jonkers et al., 2001). A complete mass balance was difficult to achieve in present study, which often occurs in similar biodegradation studies (Jonkers et al., 2001). The incomplete mass balance was possibly due to the poor extraction efficiency of $\mathrm{NP}_{\mathrm{a}}$ ${ }_{\mathrm{v} 9} \mathrm{EO}$ adsorbed on cells and the existence of some undetected metabolites. According to John and White (1998), in the non-oxidative pathway, the first step in the EO chain removal by strain
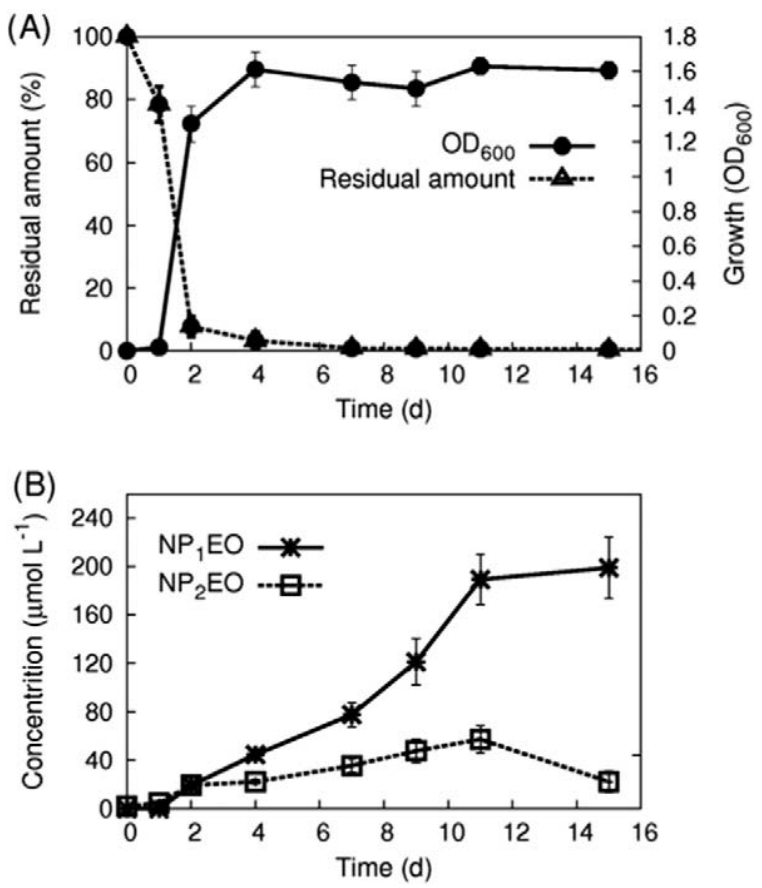

Fig. 3. Utilization of $\mathrm{NP}_{\mathrm{av} 9} \mathrm{EO}$ as a growth substrate for strain NP42a. (A) Growth was assessed based on the optical density at $600 \mathrm{~nm}\left(\mathrm{OD}_{600}\right)$. Residual amounts of NPEOs (EO chain length $n>3$ ) were determined by LC-MS analysis of organic extracts of the entire culture medium. (B) Changes in the concentration of $\mathrm{NP}_{1} \mathrm{EO}$ and $\mathrm{NP}_{2} \mathrm{EO}$ in the culture media during the incubation of strain NP42a. Values represent the means of duplicate experiments, the standard deviations were too small to illustrate in some cases.

Pseudomonas putida is a hydroxyl shift from the terminal to the penultimate carbon to produce a labile hemiacetal, which results in the stepwise release of $\mathrm{C}_{2}$ units as acetaldehyde to form the corresponding NPEOs with shorter EO chains. As shown in Table 1, acetaldehyde was identified as the major aldehydic compound formed in the reaction of $\mathrm{NP}_{\mathrm{av} 9} \mathrm{EO}$ with the NP42a cell extract (Table 1), which further demonstrates that the EO chain was shortened via a non-oxidative hydroxyl shift cleavage pathway (Fig. 1A). 
Table 1

The formation of acetaldehyde $(\mathrm{mM})$ from the reaction of cell extracts with $\mathrm{NP}_{\mathrm{avg}} \mathrm{EO}$ by NPEO-degrading isolates ${ }^{\mathrm{a}}$.

\begin{tabular}{lll}
\hline Bacterial strain & Substrate & \\
\cline { 2 - 3 } & $\mathrm{NP}_{\mathrm{av} 9} \mathrm{EO}$ & $\mathrm{AEO}_{8}$ \\
\hline $\mathrm{NP42a}$ & 0.86 & 0.24 \\
$\mathrm{NP15b}$ & 0.13 & 0.03 \\
$\mathrm{NP47a}$ & $\mathrm{ND}$ & $\mathrm{ND}$ \\
\hline
\end{tabular}

a Other aldehydic compounds such as glyoxylic acid were not detected in the reaction of cell extracts with $\mathrm{NP}_{\mathrm{av} 9} \mathrm{EO}$ and $\mathrm{AEO}_{8}$ by any NPEO-degrading isolates. $\mathrm{ND}=$ not detected.

As shown in Table 1, aldehyde was also formed during the reaction of $\mathrm{AEO}_{8}$ with the NP42a cell extract, which suggests that NP42a can degrade a wide spectrum of compounds with similar structures via the non-oxidative pathway (White et al., 1996; Di Corcia et al., 1998b; Lu et al., 2008).

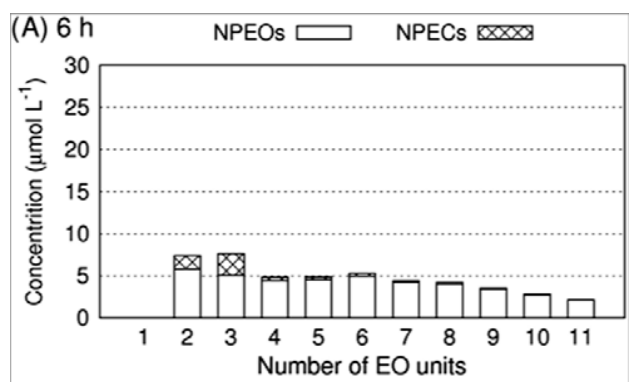

(B) $12 \mathrm{~h}$

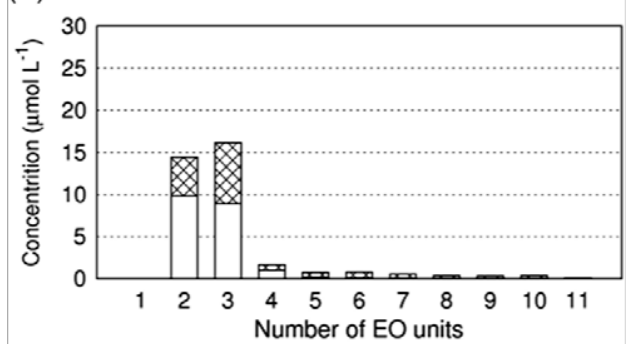

(C) $24 \mathrm{~h}$

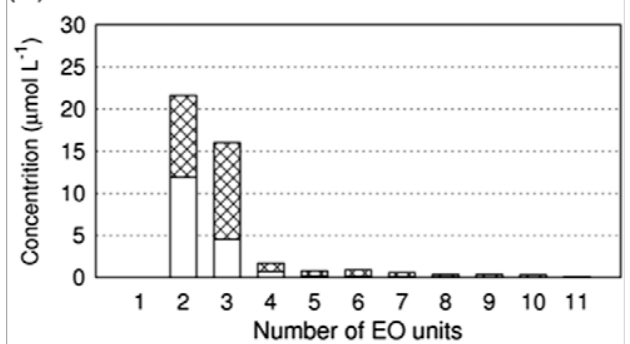

(D) $96 \mathrm{~h}$

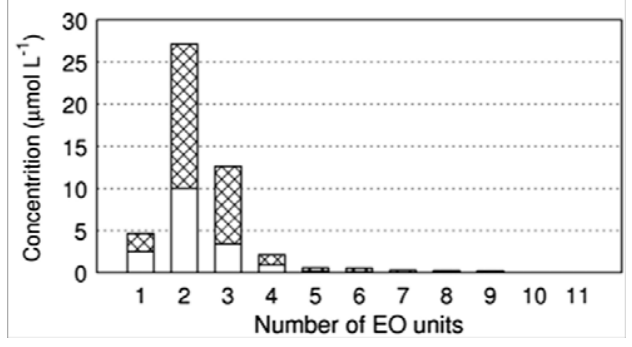

Fig. 4. Changes in the distribution of individual NPEO metabolites (NPEOs and NPECs) during $\mathrm{NP}_{11} \mathrm{EO}\left(50 \mu \mathrm{mol} \mathrm{L}^{-1}\right)$ biodegradation by strain NP15b for (A) 6 , (B) 12, (C) 24 and (D) $96 \mathrm{~h}$.
On the other hand, $\mathrm{NP}_{2,3} \mathrm{EO}$ have been found to be the dominant degradation products through the hydroxyl shift cleavage pathway in most of the studies (John and White, 1998, as shown in Fig. 1A). Few pure strains that are capable of converting NPEOs to $\mathrm{NP}_{1} \mathrm{EO}$, which has been regarded as the most toxic and estrogenic NPEO homologue (Servos, 1999; Metcalfe et al., 2001) and is widely found in many environments as the main metabolites of NPEOs (Ahel et al., 1994; Ferguson et al., 2001; Kolpin et al., 2002), have been isolated to date. Nishio et al. (2005) isolated a bacterial strain belonging to the genus Sphingomonas that could produce $\mathrm{OP}_{1} \mathrm{EO}$ through the degradation of OPEOs. However, they found that a high ratio of $\mathrm{OP}_{2} \mathrm{EO}$ existed in the degradation products (the ratio of $\mathrm{NP}_{1} \mathrm{EO}: \mathrm{NP}_{2} \mathrm{EO}$ was 2.2:1 on day 7 ), which is different from the results of the present study. Liu et al. (2006) also isolated two strains (Ensifer sp. strain AS08 and Pseudomonas sp. strain AS90) capable of transforming $\mathrm{NP}_{2} \mathrm{EO}$ to $\mathrm{NP}_{1} \mathrm{EO}$. Overall, this is the first study to report the transformation of long chain NPEOs by a pure culture with $\mathrm{NP}_{1} \mathrm{EO}$ as the major metabolite. The suggested NPEO-degradation pathway is shown in Fig. 5A.

\subsubsection{Pathway 2: hydroxyl shift cleavage of NPEOs followed by terminal oxidation of the EO chain}

The biodegradation of $\mathrm{NP}_{11} \mathrm{EO}$ by resting strain $\mathrm{NP} 15 \mathrm{~b}$ is shown in Fig. 4. $\mathrm{NP}_{11} \mathrm{EO}$ was transformed into $\mathrm{NP}_{2-10} \mathrm{EO}$ and a small amount of $\mathrm{NP}_{2-10} \mathrm{EC}$ (about 13\% molar percentage) within $6 \mathrm{~h}$ of culture. NPEOs with an EO chain length greater than four almost disappeared, while $\mathrm{NP}_{4-10} \mathrm{EC}$ remained almost unchanged around 5.6-9.2\% after incubation for $12 \mathrm{~h}$. At the same time, $\mathrm{NP}_{2-3} \mathrm{EO}$ (about 39-53\%) and $\mathrm{NP}_{2-3} \mathrm{EC}$ (about 35-49\%) became the predominant products. After incubation for $96 \mathrm{~h}$, a small amount of $\mathrm{NP}_{1} \mathrm{EO}$ (about 5.1\%) and $\mathrm{NP}_{1} \mathrm{EC}(4.4 \%)$ appeared, and the concentration of $\mathrm{NP}_{2-3} \mathrm{EC}$ accounted for approximately $54 \%$ of the total intermediates. No $\mathrm{NP}_{11} \mathrm{EC}$ was detected throughout the degradation period. A mass balance at different sampling times for strain NP15b was summarized in Table S3 (Supplementary Material). The main metabolites detected $\left(\mathrm{NP}_{1-10} \mathrm{EO}\right.$ and $\left.\mathrm{NP}_{1-10} \mathrm{EC}\right)$ accounted for

(A)

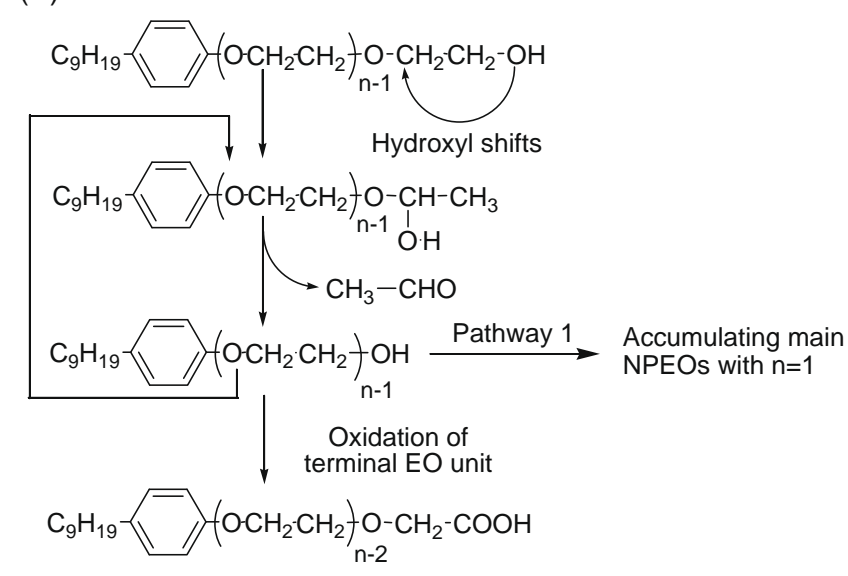

(B)

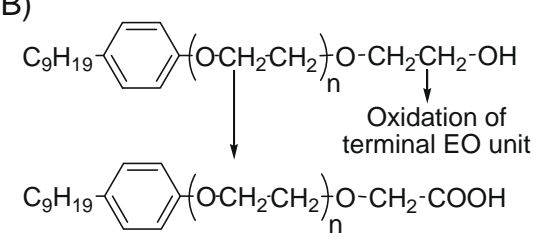

Fig. 5. Biodegradation pathways of NPEOs proposed based on the results of this study. (A) hydroxyl shift cleavage-oxidation model, and (B) terminal oxidation model (non shortening). The exact structure of the alkyl chain is not specified. 
about $71-96 \%$ molar percentage of $\mathrm{NP}_{11} \mathrm{EO}$ transformed during 96 h. Strains NP41b, NP22b, NP213b, NP426a, and NP31a showed NPEO-degradation behavior similar to NP15b.

As shown in Table 1, acetaldehyde was also the major aldehydic compound produced in the reaction of cell extract with $\mathrm{NP}_{\mathrm{av} 9} \mathrm{EO}$ by strain NP15b. So it is speculated that the degradation of $\mathrm{NP}_{11} \mathrm{EO}$ was divided into two main steps: shortening of the EO chain via a hydroxyl shift during the first step and terminal oxidation of the short-chain NPEOs to short chain NPECs without the liberation of glyoxylic acid. The suggested pathway is shown in Fig. 5A. Because six of the eight isolated strains with high phylogenetically diversity showed similar NPEO-degrading patterns, it is reasonable to assume that Pathway 2 might be a major mechanism involved in the degradation of NPEOs in the environment, which is also consistent with the observations of aerobic biodegradation of NPEOs in mixed cultures and environments (Ahel et al., 1994; Di Corcia et al., 1998a; Montgomery-Brown and Reinhard, 2003).

\subsubsection{Pathway 3: direct oxidation of NPEOs without the cleavage of EO chain}

It is interesting to note that strain NP47a exhibited the ability to transform $\mathrm{NP}_{11} \mathrm{EO}$ to its corresponding carboxylated products $\left(\mathrm{NP}_{11} \mathrm{EC}\right)$ without the cleavage of the EO chains (Fig. 6). On day 7 , the concentration of $\mathrm{NP}_{11} \mathrm{EC}$ and $\mathrm{NP}_{11} \mathrm{EO}$ reached 19.6 and $23.4 \mu \mathrm{mol} \mathrm{L}^{-1}$, accounting for $40 \%$ and $50 \%$ of the initial $\mathrm{NP}_{11} \mathrm{EO}$ concentration respectively. The remaining $10 \%$ might be an error margin or due to the existence of some undetected metabolites, such as CAPECs. The degradation rate and the bacterial growth rate were both relatively low, perhaps because the energy gained from oxidation of the terminal alcohol group was much lower than the stepwise ether cleavage. As shown in Table 1, none of the aldehydic compounds were produced in the reaction of NP47a cell extract with $\mathrm{NP}_{\mathrm{av} 9} \mathrm{EO}$ or $\mathrm{AEO}_{8}$. These findings indicate that the biodegradation of the NPEOs by strain NP47a exhibited a novel oxidation pathway as shown in Fig. 5B.

To date, all studies conducted to evaluate the biodegradation of NPEOs by pure cultures have shown that degradation proceeds via the successive exo-cleavage of the EO chain. Although NPECs with long EO chains have not been widespread in the environment (Ying et al., 2002; Montgomery-Brown and Reinhard, 2003; Komori et al., 2006), the formation of NPECs without ether cleavage has also been observed in some studies (Di Corcia et al., 1994; Jonkers et al., 2001; Hayashi et al., 2005). For example, Jonkers et al. (2001) found that mid-chain NPECs with the same distribution profile as the added NPEOs occurred as the most abundant species at the beginning of their biodegradation experiment in river water. Hayashi et al. (2005) found that NPEOs were oxidized to the corresponding NPECs instead of shortened in the presence of organic materials such as methanol, glucose, and yeast extract. Di Corcia et al. (1994) found that the concentration of NPECs with long EO

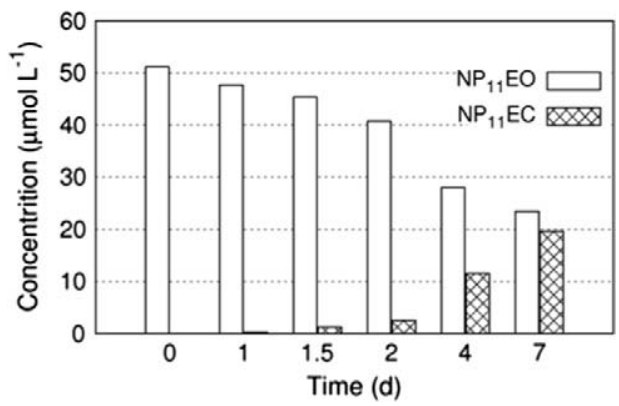

Fig. 6. Time course of $\mathrm{NP}_{11} \mathrm{EO}$ biodegradation and the formation of metabolites by strain NP47a. chains in the secondary effluents of a major WWTP in Italy remained high over 1 year of monitoring. Therefore, NP47a may represent a small group of bacteria capable of transforming long chain NPEOs directly to the corresponding NPECs under special environmental conditions.

At the same time, strain NP47a was also found to be capable of degrading short chain of NPEOs $\left(\mathrm{NP}_{\mathrm{av} 2} \mathrm{EO}, n=1,2\right.$, and 3$)$ to CAPEC in another study (data not shown), further showing that this isolate possesses a high oxidation ability.

\section{Conclusions}

Phylogenetically diverse NPEO-degrading strains were isolated from activated sludge by using a cultivation strategy characterized by the use of gellan gum as a gelling reagent and a low concentration of target carbon source. Among the eight NPEO-degrading isolates, six isolates with high phylogenetic diversity were found to degrade NPEOs via hydroxyl shift cleavage of NPEOs followed by terminal oxidation of the EO chain, suggesting that this pathway is a major mechanism for the degradation of NPEOs in diverse environments. At the same time, there exist two other pathways: a non-oxidative pathway with nonylphenol monoethoxylate $\left(\mathrm{NP}_{1} \mathrm{EO}\right)$ as the dominant product, and an oxidative one by oxidizing NPEOs directly without the cleavage of EO chains.

\section{Acknowledgments}

This work was supported by the National Natural Science Foundation of China (Nos. 50921064, 50578153) and the Ministry if Science and Technology of the People's Republic of China (No. 2006DFA91870).

\section{Appendix A. Supplementary material}

Supplementary data associated with this article can be found, in the online version, at doi:10.1016/j.chemosphere.2010.04.044.

\section{References}

Ahel, M., Giger, W., 1985. Determination of nonionic surfactants of the alkylphenol polyethoxylate type by high-performance liquid chromatography. Anal. Chem. 57, 2584-2590.

Ahel, M., Koch, M., Giger, W., 1994. Behaviour of alkylphenol polyethoxylate surfactants in the aquatic environment-I. Occurrence and transformation in sewage treatment. Water Res. 28, 1131-1142.

Barberio, C., Pagliai, L., Cavalieri, D., Fani, R., 2001. Biodiversity and horizontal gene transfer in culturable bacteria isolated from activated sludge enriched in nonylphenol ethoxylates. Res. Microbiol. 152, 105-112.

Chen, H.J., Tseng, D.H., Huang, S.L., 2005. Biodegradation of octylphenol polyethoxylate surfactant Triton $\mathrm{X}-100$ by selected microorganisms. Bioresour. Technol. 96, 1483-1491.

Crescenzi, C., Di Corcia, A., Samperi, R., Marcomini, A., 1995. Determination of nonionic polyethoxylate surfactants in environmental waters by liquid chromatography/electrospray mass spectrometry. Anal. Chem. 67, 1797-1804.

Di Corcia, A., Samperi, R., Marcomini, A., 1994. Monitoring aromatic surfactants and their biodegradation intermediates in raw and treated sewages by solid-phase extraction and liquid chromatography. Environ. Sci. Technol. 28, 850-858.

Di Corcia, A., Costantino, A., Crescenzi, C., Marinoni, E., Samperi, R., 1998a. Characterization of recalcitrant intermediates from biotransformation of the branched alkyl side chain of nonylphenol ethoxylate surfactants. Environ. Sci. Technol. 32, 2401-2409.

Di Corcia, A., Crescenzi, C., Marcomini, A., Samperi, R., 1998b. Liquid chromatography electrospray mass spectrometry as a valuable tool for characterizing biodegradation intermediates of branched alcohol ethoxylate surfactants. Environ. Sci. Technol. 32, 711-718.

Ferguson, P.L., Iden, C.R., Brownawell, B.J., 2001. Distribution and fate of neutral alkylphenol ethoxylate metabolites in a sewage-impacted urban estuary. Environ. Sci. Technol. 35, 2428-2435.

Ferrari, B.C., Binnerup, S.J., Gillings, M., 2005. Microcolony cultivation on a soil substrate membrane system selects for previously uncultured soil bacteria. Appl. Environ. Microbiol. 71, 8714-8720.

Gonzalez, S., Petrovic, M., Barcelo, D., 2007. Removal of a borad range of surfactants from municipal wastewater-comparison between membrane bioreactor and conventional activated sludge treatment. Chemosphere 67, 335-343. 
Hanada, S., Hiraishi, A., Shimada, K., Matsuura, K., 1995. Chloroflexus aggregans sp. nov., a filamentous phototrophic bacterium which forms dense cell aggregates by active gliding movement. Int. J. Syst. Bacteriol. 45, 676-681.

Hayashi, S., Saito, S., Kim, J.H., Nishimura, O., Sudo, R., 2005. Aerobic biodegradation behavior of nonylphenol polyethoxylates and their metabolites in the presence of organic matter. Environ. Sci. Technol. 39, 5626-5633.

Isobe, T., Nishiyama, H., Nakashima, A., Takada, H., 2001. Distribution and behavior of nonylphenol, octylphenol and nonylphenol monoethoxylate in Tokyo metropolitan area: their association with aquatic particles and sedimentary distributions. Environ. Sci. Technol. 35, 1041-1049.

Janssen, P.H., Yates, P.S., Grinton, B.E., Taylor, P.M., Sait, M., 2002. Improved culturability of soil bacteria and isolation in pure culture of novel members of the divisions Acidobacteria, Actinobacteria, Proteobacteria, and Verrucomicrobia. Appl. Environ. Microbiol. 68, 2391-2396.

Jobling, S., Sheahan, D., Osborne, J.A., Matthiessen, P., Sumpter, J.P., 1996. Inhibition of testicular growth in rainbow trout (Oncorhynchus mykiss) exposed to estrogenic alkylphenolic chemicals. Environ. Toxicol. Chem. 15, 194-202.

John, D.M., White, G.F., 1998. Mechanism for biotransformation of nonylphenol polyethoxylates to xenoestrogens in Pseudomonas putida. J. Bacteriol. 180, 4332-4338.

Jonkers, N., Knepper, T.P., De Voogt, P., 2001. Aerobic biodegradation studies of nonylphenol ethoxylates in river water using liquid chromatographyelectrospray tandem mass spectrometry. Environ. Sci. Technol. 35, 335340.

Koh, Y.K.K., Chiu, T.Y., Boobis, A.R., Cartmell, E., Pollard, S.J.T., Scrimshaw, M.D., Lester, J.N., 2008. A sensitive and robust method for the determination of alkylphenol polyethoxylates and their carboxylic acids and their transformation in a trickling filter wastewater treatment plant. Chemosphere 73, 551-556.

Kolpin, D.W., Furlong, E.T., Meyer, M.T., Thurman, E.M., Zaugg, S.D., Barber, L.B. Buxton, H.T., 2002. Pharmaceuticals, hormones, and other organic wastewater contaminants in US streams, 1999-2000: a national reconnaissance. Environ. Sci. Technol. 36, 1202-1211.

Komori, K., Okayasu, Y., Yasojima, M., Suzuki, Y., Tanaka, H., 2006. Occurrence of nonylphenol, nonylphenol ethoxylate surfactants and nonylphenol carboxylic acids in wastewater in Japan. Water Sci. Technol. 53, 27-33.

Lane, D., 1991. 16S/23S rRNA sequencing. In: Stackebrandt, E., Goodfellow, M. (Eds.) Nucleic Acids Techniques in Bacterial Systematics. John Wiley \& Sons, Chichester, United Kingdom, pp. 115-147.

Liu, X., Tani, A., Kimbara, K., Kawai, F., 2006. Metabolic pathway of xenoestrogenic short ethoxy chain-nonylphenol to nonylphenol by aerobic bacteria, Ensifer sp. strain AS08 and Pseudomonas sp. strain AS90. Appl. Microbiol. Biotechnol. 72, 552-559.

Lozada, M., Itria, R.F., Figuerola, E.L.M., Babay, P.A., Gettar, R.T., de Tullio, L.A., Erijman, L., 2004. Bacterial community shifts in nonylphenol polyethoxylatesenriched activated sludge. Water Res. 38, 2077-2086.

Lozada, M., Figuerola, E.L.M., Itria, R.F., Erijman, L., 2006. Replicability of dominant bacterial populations after long-term surfactant-enrichment in lab-scale activated sludge. Environ. Microbiol. 8, 625-638.

Lu, J., Jin, Q., He, Y., Wu, J., Zhao, J., 2008. Biodegradation of nonylphenol ethoxylates by Bacillus sp LY capable of heterotrophic nitrification. FEMS Microbiol. Lett. 280, 28-33.

Maguire, R.J., 1999. Review of the persistence of nonylphenol and nonylphenol ethoxylates in aquatic environments. Water Qual. Res. J. Can. 34, 37-78.

Maki, H., Masuda, N., Fujiwara, Y., Ike, M., Fujita, M., 1994. Degradation of alkylphenol ethoxylates by Pseudomonas sp. strain TR01. Appl. Environ. Microbiol. 60, 2265-2271.
Metcalfe, C.D., Metcalfe, T.L., Kiparissis, Y., Koenig, B.G., Khan, C., Hughes, R.J., Croley, T.R., March, R.E., Potter, T., 2001. Estrogenic potency of chemicals detected in sewage treatment plant effluents as determined by in vivo assays with Japanese medaka (Oryzias latipes). Environ. Toxicol. Chem. 20, 297-308.

Montgomery-Brown, J., Reinhard, M., 2003. Occurrence and behavior of alkylphenol polyethoxylates in the environment. Environ. Eng. Sci. 20, 471-486.

Nagarnaik, P.M., Mills, M.A., Boulanger, B., 2010. Concentrations and mass loadings of hormones, alkylphenols, and alkylphenol ethoxylates in healthcare facility wastewaters. Chemosphere 78, 1056-1062.

Nguyen, M.H., Sigoillot, J.C., 1997. Isolation from coastal sea water and characterization of bacterial strains involved in non-ionic surfactant degradation. Biodegradation 7, 369-375.

Nishio, E., Yoshikawa, H., Wakayama, M., Tamura, H., Morita, S., Tomita, Y., 2005 Isolation and identification of Sphingomonas sp. that yields tert-octylphenol monoethoxylate under aerobic conditions. Biosci. Biotechnol. Biochem. 69, 1226-1231.

Richardson, S.D., Caughran, T.V., Poiger, T., Guo, Y.B., Crumley, F.G., 2000 Application of DNPH derivatization with LC/MS to the identification of polar carbonyl disinfection by-products in drinking water. Ozone Sci. Eng. 22, 653675.

Routledge, E.J., Sumpter, J.P., 1996. Estrogenic activity of surfactants and some of their degradation products assessed using a recombinant yeast screen. Environ. Toxicol. Chem. 15, 241-248.

Sato, H., Shibata, A., Wang, Y., Yoshikawa, H., Tamura, H., 2001. Characterization of biodegradation intermediates of non-ionic surfactants by matrix-assisted laser desorption/ionization-mass spectrometry 1. Bacterial biodegradation of octylphenol polyethoxylate under aerobic conditions. Polym. Degrad. Stab. 74, 69-75.

Sato, H., Shibata, A., Wang, Y., Yoshikawa, H., Tamura, H., 2003. Characterization of biodegradation intermediates of nonionic surfactants by MALDI-MS. 2 Oxidative biodegradation profiles of uniform octylphenol polyethoxylate in $\mathrm{O}$ 18-labeled water. Biomacromolecules 4, 46-51.

Servos, M.R., 1999. Review of the aquatic toxicity, estrogenic responses and bioaccumulation of alkylphenols and alkylphenol polyethoxylates. Water Qual. Res. J. Can. 34, 123-177.

Tamaki, H., Sekiguchi, Y., Hanada, S., Nakamura, K., Nomura, N., Matsumura, M. Kamagata, Y., 2005. Comparative analysis of bacterial diversity in freshwater sediment of a shallow eutrophic lake by molecular and improved cultivationbased techniques. Appl. Environ. Microbiol. 71, 2162-2169.

Thiele, B., Günther, K., Schwuger, M.J., 1997. Alkylphenol ethoxylates: trace analysis and environmental behavior. Chem. Rev. 97, 3247-3272.

White, G., Russell, N., Tidswell, E., 1996. Bacterial scission of ether bonds. Microbiol. Mol. Biol. Rev. 60, 216-232.

Ying, G.G., Williams, B., Kookana, R., 2002. Environmental fate of alkylphenols and alkylphenol ethoxylates a review. Environ. Int. 28, 215-226.

Zhang, J., Yang, M., Qiao, Y., Zhang, Y., Chen, M.X., 2007. Biodegradation of nonylphenoxy carboxylates mixtures in two microcosms. Sci. Total Environ. 388, 392-397.

Zhang, J., Yang, M., Zhang, Y., Chen, M.X., 2008a. Biotransformation of nonylphenol ethoxylates during sewage treatment under anaerobic and aerobic conditions. J. Environ. Sci. 20, 135-141.

Zhang, Y., Sei, K., Toyama, T., Ike, M., Zhang, J., Yang, M., Kamagata, Y., 2008b. Changes of catabolic genes and microbial community structures during biodegradation of nonylphenol ethoxylates and nonylphenol in natural water microcosms. Biochem. Eng. J. 39, 288-296. 